\title{
Potential for the Role of School-Based Animal-Assisted Literacy Mentoring Programs
}

\section{LORI FRIESEN \\ University of Alberta}

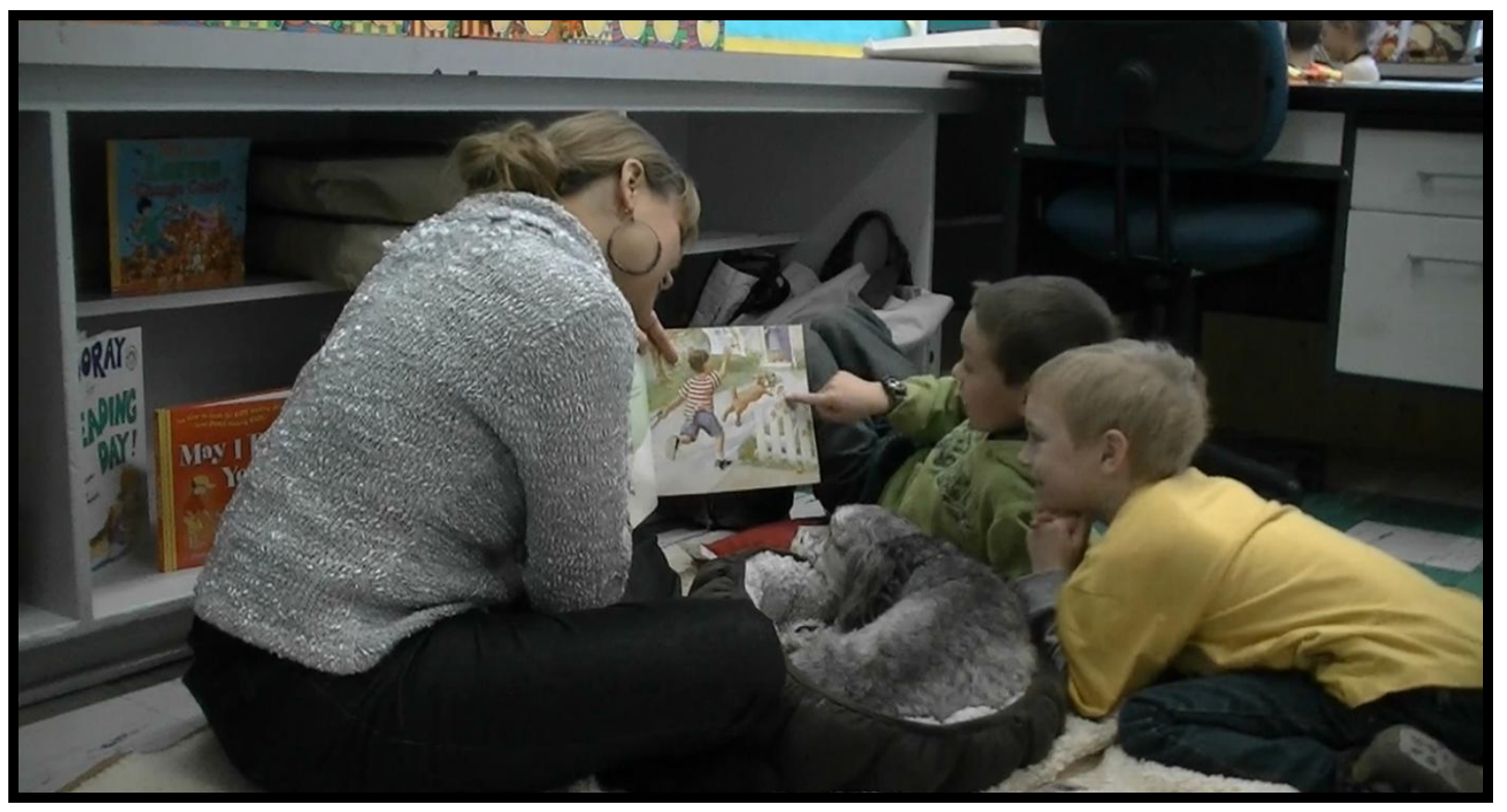

It is the sixth week that I have visited this classroom with my two dogs, Tango and Sparky. Today these boys have signed up to work with Sparky, but even before our small group settles onto the carpet at the back of the classroom to begin reading or writing, Daniel walks directly over to Sparky to tell him an urgent story about his neighbour's dog who was sick last night and who had to go to the veterinarian. As the other little boy and I listen intently to his story and ask questions, Sparky, sensing that something is wrong, gently licks Daniel's hand, looks up at him and wags his tail. Daniel smiles, and while stroking Sparky's ear, proceeds to tell him not to eat chocolate, because that's how the other dog got sick. Our small group falls into silence for a moment, and then we talk about how we need to be careful to ensure that there isn't any chocolate in their classroom for Tango and Sparky to get into. The boys then choose to read the book, Boomer Goes to School (McGeorge \& Whyte, 1996), a story about a dog who follows its owner to school and gets into all kinds of trouble. As the boys take turns reading the book to Sparky, we pause to 'teach' the dog a new word the boys are struggling with (all the while stroking him and carefully ensuring that he can see the words and pictures). As they read, our conversation is peppered with meaningful stories about the animals in these boys' lives.

Research exploring school-based literacy mentorship programs indicates that every child can benefit academically, socially, and emotionally from caring relationships with non- 
related adults (Ellis, Small-McGinley, \& De Fabrizio, 2001). Although millions of children continue to read below grade level in North America (Biancarosa \& Snow, 2006),

contemporary literacy research suggests that regular opportunities to experience and enjoy literature helps to develop students' understanding of story structure, encourages vocabulary development, and comprehension (Pressley, 2001). An emerging body of research exploring animal-assisted literacy programs suggests that companion animals, and dogs in particular, are thought to provide a non-threatening yet socially supportive and interactive audience for children when practicing their oral reading skills. International and innovative programs have been developed which pair young readers with a well-behaved and gentle animal and an adult volunteer in schools and libraries. Although further research is required to explore what the significance of these programs may be for young learners, anecdotal evidence from educators and parents who have participated in Reading Education Assistance Dog (R.E.A.D.) programs suggest that the children's enthusiasm and confidence towards reading to the animals carries over into their classroom experience because the dogs are able to offer "a wonderful combination of kindness, curiosity, and patience to the task of reading" (Intermountain Therapy Animals, 2010). As indicated by promising pilot studies, the unconditional acceptance offered by a gentle animal seems to positively influence self-confidence and a child's willingness to read (Intermountain Therapy Animals, 2010).

The Intermountain Therapy Animals Association, in its organizational mission statement, emphasizes that the goal of their R.E.A.D. program is to "improve the literacy skills of children through the assistance of registered therapy teams as literacy mentors " $"(2010)$. Current research examining school-based ${ }^{2}$ mentorship programs involving children and nonrelated adults suggests that the term 'literacy mentor' indicates potential for the development of a meaningful relationship between the participating adult and the child. However, although organizers of most animal-assisted literacy programs would likely agree that children involved in these programs require the attentive support and assistance of an adult while reading with and to the dog, the relationship most commonly emphasized is the bond that the child will likely establish with the dog. Drawing on contemporary studies exploring school-based mentoring programs, this article examines how mentorship research can inform and inspire possibilities for child-adult relationship development within animal-assisted literacy programs, and suggests how animal-assisted mentoring may provide unique and valuable educational, emotional, and social support for children in the elementary language arts classroom context.

\section{School-Based Mentorship Programs Defined}

It is helpful to begin with a brief overview of the distinguishing features of schoolbased mentoring programs to highlight the similarities and differences between human-only programs and animal-assisted literacy programs. A compelling field of research exploring school-based mentoring programs suggests that providing children with regular opportunities to interact with a non-related adult role model can provide many positive benefits for students academically, socially, and/or emotionally (Dappen \& Isernhagen, 2006; de Anda, 2001; Ellis,

\footnotetext{
1 The term therapy dog, in the context of these programs, means that the dog is over one year of age, has completed basic obedience training and has been evaluated for having an appropriate temperament for working with children, has veterinary certification of excellent health and is vaccinated, is well-groomed, calm, and gentle (I.T.A., 2010).

${ }^{2}$ The term school based means that "the mentoring activities occurred in the school setting only during the academic year" (Randolph \& Johnson, 2008, p. 178).
} 
Hart, \& Small-McGinley, 1998; Randolph \& Johnson, 2008; Rhodes, 2002). School-based mentoring programs vary widely in the frequency of contact required between mentor and protégé as well as in the length of the program. However, Small-McGinley (2000) notes that the majority of school-based mentoring programs require a one-on-one relationship between the mentor and protégé, developed over time through regular weekly meetings. Although many mentoring programs can last for one to two years (Small-McGinley, 2000), research demonstrates that programs lasting for as short as three months with weekly one-hour meetings between mentor and protégé can offer significant academic and social/emotional benefits for children (Ellis, Small-McGinley, \& De Fabrizio, 2001).

Within various programs the definition of mentorship reflects the range of intentions and the targeted population of each program. Some programs view the role of the mentor as tutor with a focus primarily on improving student academic performance. Others place the quality of the relationship between the mentor and protégé as their priority, while still others strive for a balance between supporting children academically and emotionally and/or socially (Small-McGinley, 2000). However, even in programs where a heavy emphasis is placed on the mentor tutoring the child, it is essential to remember that it is not the volunteer's role or responsibility to teach the child how to read. Rather, the mentor's role is to foster enjoyment in literacy through involving the child in gentle engagement activities, while thoughtfully attending to the development of a meaningful relationship between adult and child (Ellis, Small-McGinley, \& De Fabrizio, 2001).

Brodkin and Coleman (1996) define mentorship with a dual focus on relationship as well as academics, as "one who provides one-to-one support and attention, is a friend and role model, boosts a child's self-esteem, enhances a student's educational experience" (p. 21). Although "all children need supportive interaction with caring adults to learn and grow" (Ellis, Small-McGinley, \& De Fabrizio, 2001, p. 43), Randolph and Johnson (2008) highlight that the majority of mentoring programs available to youth are designed as selective programs for youth who are at a "slightly elevated risk status relative to their peers" (p. 179). This observation is supported by DuBois, Holloway, Valentine, and Cooper (2002), who emphasize that many mentoring programs are designed to pair non-related ${ }^{3}$ adult mentors with children who have been identified as being 'at risk' by their teachers (who may be struggling academically or socially), children who come from single-parent homes, or for children of varying ethnic minorities, while other mentoring programs are open to all children (Randolph \& Johnson, 2008).

\section{Animal-Assisted Literacy Mentorship Programs Defined}

It is clear that although a range of school-based mentoring programs exist, there is a great deal of potential for children to benefit emotionally, socially, and academically through regular caring interaction with a non-related adult mentor. Over the past ten years, a burgeoning field of research exploring human-animal interaction in psychology, counselling and special-needs education suggests that many benefits are associated with providing children with regular opportunities for supervised interaction with a calm, trained, and wellgroomed animal, and with dogs in particular (Nimer \& Lundahl, 2007). It is intriguing to

\footnotetext{
${ }^{3}$ It is not my intention to privilege 'non-related' adult mentors above 'related' mentors in a child's life. It is of course possible that one student's parent or relative could serve as an adult mentor to not only that child but to other students in the class/school who may or may not have positive 'natural' mentors in their lives.
} 
explore the possibilities for how the inclusion of a dog in school-based mentoring programs involving children and non-related adult mentors might offer children unique educational, emotional, and social support in the school context.

The theoretical basis of animal-assisted programs rests on a concept which is becoming increasingly well-known as the human-animal bond. This concept was initially proposed by veterinarians (Hines, 2003) and later conceptualized by Edward O. Wilson, a Pulitzer Prize winner and science professor at Harvard University, in his landmark book Biophilia (Wilson, 1984) and later the Biophilia Hypothesis (Kellert \& Wilson, 1993). Biophilia is defined by Wilson (1984) as an "innate tendency to focus on life and lifelike processes" (p. 1) due to humans' deep and complex connection with other organisms in the natural world. Wilson (1993) emphasizes that as humans, our relationship with the natural world is historically and biologically based. In fact, he notes that:

for more than $99 \%$ of human history people have lived in hunter-gatherer bands totally and intimately involved with other organisms. During this period of deep history, and still farther back, into paleohominid times, they depended on an exact learned knowledge of crucial aspects of natural history....In short, the brain evolved in a biocentric world, not a machine-regulated world (Wilson, 1993, p. 32).

Wilson (1993) emphasizes that humans' relationship with nature elevates and enriches our own existence and as humans, we are drawn to nature because we recognize ourselves within it. In support of the biophilia hypothesis, Kellert (1993) states that "the human need for nature is linked not just to the material exploitation of the environment but also to the influence of the natural world on our emotional, cognitive, aesthetic, and even spiritual development. . . [M] uch of the human search for a coherent and fulfilling existence is intimately dependent on our relationship to nature" (pp. 42-43).

Children have a natural fascination with nature. Whether it is bringing in worms from the playground at recess or becoming instantly attached to a stray kitten, children are often drawn to the natural world. A burgeoning field of research exploring the human-animal bond between children and animals suggests that dogs may be able to offer a unique form of support for children's learning and development in the school and classroom environment due to their non-judgemental yet highly social nature (Esteves \& Stokes 2008; Friesen, 2009; Jalongo, Astorino \& Bomboy, 2004; Limond, Bradshaw \& Cormack, 1997).

Established in November, 1999, and based out of Utah, U.S.A., the largest known organization of this nature is the Intermountain Therapy Animals Association (I.T.A.). The I.T.A. trains and supports more than 550 Reading Education Assistance Dogs (R.E.A.D.) and their owners working as 'literacy mentor teams' in schools and libraries in 43 states in the U.S. and in British Columbia, Canada (R.E.A.D., 2007). A complete listing of R.E.A.D. affiliate programs is available on their website: http://www.therapyanimals.org/Find-Local-READPrograms-and-Regional-Workshops.html As an affiliate organization of the Delta Society, I.T.A. requires that the person end of the leash receives training as well as the animal. Numerous organizations that are not formally affiliated with the I.T.A. run similar programs, many of which are based on the I.T.A. model. However, programs designed to provide children with opportunities to read with and to dogs in schools and/or libraries are not strictly a North-American phenomenon. As is illustrated Figure 1, there are a growing number of animal-assisted literacy organizations in countries such as Asia, Australia, and India. ${ }^{4}$ Perhaps

\footnotetext{
${ }^{4}$ Although this list is likely not exhaustive, it offers a sampling of the wide range of animal-assisted literacy programs currently running in schools and/or libraries in various countries.
} 
most surprising is the relatively new Professor Paws animal-assisted literacy program in schools in Guangzhou, China, as dogs in this region are commonly viewed as a food source (Animals Asia Foundation, 2010). The growing popularity of programs such as these demonstrates the varied positive roles that dogs are playing in human lives in countries around the world.

Similar to traditional mentoring programs, school-based animal-assisted literacy programs vary widely in the frequency of contact between the child and literacy mentor team and in the length of the program, in addition to the population targeted within each program (R.E.A.D., 2007). While some programs are designed to focus on children who have been identified to be at-risk either socially or academically, others are open to any interested students. Some programs focus specifically on the needs of children in grades K-3 while others are open to children up to grade 6. Like many traditional mentoring programs, the focus in these programs is on academics, and on reading in particular. However, the relationship most commonly emphasized in animal-assisted reading programs is the developing bond between the child and the dog, with less attention placed on the potential relationship between the non-related adult and the child. Further, the power of animal-assisted literacy programs at least in part lies in the fact that the dogs "sit there and don't interrupt. They don't ask questions like people" (Intermountain Therapy Animals, 2010).

Figure 1

Listings of North American and Overseas Animal-Assisted Literacy Organizations

(Programs that have self-identified as I.T.A. R.E.A.D. affiliates are marked with an asterisk.)

\begin{tabular}{|l|l|l|}
\hline \multicolumn{2}{|c|}{ Canada } \\
\hline \multicolumn{1}{|c|}{ Program Name } & \multicolumn{1}{|c|}{ Location } & \multicolumn{1}{c|}{ Website } \\
\hline PAWS for a Story & $\begin{array}{l}\text { Edmonton, AB } \\
\text { http://www.pettherapysociety.com/programs/paws- } \\
\text { for-a-story/ } \\
\text { http://www.nvsd44.bc.ca/SchoolSites/Westview/Pro } \\
\text { grams/PAWS1.aspx } \\
\text { haws for Reading*//www.tpoc.ca/ChildrensPrograms.aspx }\end{array}$ \\
$\begin{array}{ll}\text { Paws to Read, } \\
\text { Therapeutic Paws of } \\
\text { Canada }\end{array}$ & $\begin{array}{l}\text { Gibsons, BC, } \\
\text { Halifax \& Sydney, NS, } \\
\text { Toronto, ON, } \\
\text { Charlottetown, PEI, } \\
\text { Montreal, QU } \\
\text { Kitchener-Waterloo, ON }\end{array}$ & \\
\hline
\end{tabular}

\begin{tabular}{|l|l|l|}
\hline \multicolumn{2}{|c|}{ United States } \\
\hline $\begin{array}{l}\text { Program Name } \\
\begin{array}{l}\text { BARK (Beach } \\
\text { Animals Reading } \\
\text { with Kids) }\end{array}\end{array}$ & $\begin{array}{l}\text { Southern California } \\
\text { (numerous locations) }\end{array}$ & \multicolumn{1}{c|}{ http://bark.web.officelive.com/currentlocations.aspx } \\
$\begin{array}{l}\text { Bideawee's Reading } \\
\text { to Dogs }\end{array}$ & $\begin{array}{l}\text { Long Island and } \\
\text { Manhattan, NY }\end{array}$ & $\begin{array}{l}\text { http://www.bideawee.org/programs_\&_services/lea } \\
\text { rning_centers/reading_to_dogs.php }\end{array}$ \\
\hline
\end{tabular}




\begin{tabular}{|c|c|c|}
\hline Librarydogs.com* & $\begin{array}{l}\text { Illinois, Iowa, Montana, } \\
\text { Ohio,Texas, \& } \\
\text { Wisconsin }\end{array}$ & http://www.librarydogs.com/why_dogs.html \\
\hline $\begin{array}{l}\text { Love on a Leash: } \\
\text { Paws to Read }\end{array}$ & $\begin{array}{l}\text { Southern California } \\
\text { (numerous locations) }\end{array}$ & http://www.loveonaleash.org/pages/what.html \\
\hline $\begin{array}{l}\text { Mo-Kan Pet } \\
\text { Partners* }\end{array}$ & Kansas & http://www.mo-kanpetpartners.org/read.html \\
\hline Pals with Paws* & Elk Rapids, MI & http://palspaws.com/readprogram.html \\
\hline $\begin{array}{l}\text { Partners Achieving } \\
\text { Literacy (P.A.L.) }\end{array}$ & Huntsville, AL & $\begin{array}{l}\text { http://www.therapypartners.org/ } \\
\text { our_programs/our_programs_pal.htm }\end{array}$ \\
\hline Paws for Reading & Newark, DE & $\begin{array}{l}\text { http://sites.google.com/site/pawsforpeople/paws- } \\
\text { for-reading }\end{array}$ \\
\hline Paws 4 Reading* & Louisiana & $\begin{array}{l}\text { http://www.pawsnela.org/pet_therapy_paws4readin } \\
\text { g.htm }\end{array}$ \\
\hline Paws to Read & Rifle, CO & http://www.riflelibraryfriends.org/pawstoread.html \\
\hline Reading Paws* & $\begin{array}{l}\text { Alabama, Florida, } \\
\text { Georgia, \&Tennessee }\end{array}$ & http://www.readingpaws.org/ \\
\hline $\begin{array}{l}\text { Reading with } \\
\text { Rover* }\end{array}$ & Washington, DC & http://www.readingwithrover.org/ \\
\hline $\begin{array}{l}\text { Reading Pals with } \\
\text { Paws }\end{array}$ & $\begin{array}{l}\text { Southern California and } \\
\text { Colorado }\end{array}$ & http://www.paw-pals.org/page/page/1408434.htm \\
\hline $\begin{array}{l}\text { Rocky Mountain } \\
\text { R.E.A.D. Program* }\end{array}$ & Denver, CO & http://www.rockymountainread.org/ \\
\hline Sit Stay Read & Chicago, IL & http://www.sitstayread.org/ \\
\hline Story Tails* & Plainville, CT & http://www.tailsofjoy.org/pages/read.htm \\
\hline $\begin{array}{l}\text { Tail Waggin Tutors, } \\
\text { Therapy Dogs } \\
\text { International }\end{array}$ & Flanders, NJ & $\begin{array}{l}\text { http://www.tdi-dog.org/OurPrograms. } \\
\text { aspx?Page=Children+Reading+to+Dogs }\end{array}$ \\
\hline $\begin{array}{l}\text { Tales of Joy } \\
\text { R.E.A.D. Program* }\end{array}$ & New Mexico & http://www.talesofjoyread.com/Home.html \\
\hline Therapy Dogs Inc. & Cheyenne, WY & http://www.therapydogs.com/index.aspx \\
\hline
\end{tabular}

\begin{tabular}{|c|c|c|}
\hline \multicolumn{3}{|c|}{ Overseas } \\
\hline Program Name & Location & Website \\
\hline $\begin{array}{l}\text { Newspaper in } \\
\text { Education }\end{array}$ & $\begin{array}{l}\text { Vidya Valley, Pashan, } \\
\text { India }\end{array}$ & http://www.animalangels.org.in/aa/Times-NIE.htm \\
\hline Pets for Therapy & Gold Coast, Australia & http://www.gallerygiselle.com/petcontact.htm \\
\hline $\begin{array}{l}\text { The Reading Lab, } \\
\text { Assistance Dogs } \\
\text { Australia }\end{array}$ & $\begin{array}{l}\text { Sydney and Melbourne, } \\
\text { Australia }\end{array}$ & $\begin{array}{l}\text { http://www.assistancedogs.org.au/news.php?newsid } \\
=17\end{array}$ \\
\hline $\begin{array}{l}\text { Professor Paws, } \\
\text { Animals Asia } \\
\text { Foundation }\end{array}$ & $\begin{array}{l}\text { Hong Kong, China, } \\
\text { Malaysia, Philippines, } \\
\text { Japan, India, and } \\
\text { Taiwan }\end{array}$ & $\begin{array}{l}\text { http://www.animalsasia.org/index.php?UID=9LQ3 } \\
\text { T5ZA1386 }\end{array}$ \\
\hline
\end{tabular}

Initial Development of the Child-Mentor Relationship 
Contradicting mentorship research showing that the relationship would likely deepen and be strengthened over time if attention were focused on the development of a meaningful relationship between the child, the adult and the dog, the R.E.A.D. Team Training Manual (2007) has "[cut] back to four-week programs a couple times per year, or once-amonth sessions because the program "becomes commonplace and therefore less appreciated" (p. 58). If the emphasis in animal-assisted literacy programs were on the development of a genuine, caring relationship between the adult, child, and dog, it seems less likely that the initial interest and novelty would wear off. .

This emphasis on relationship development has intriguing implications for how the dog may be incorporated into mentoring experiences. Ellis, Small-McGinley, and De Fabrizio (2001) emphasize that from the beginning of a mentorship program, the mentor's sustained attention to establishing a nurturing, trusting relationship with the child is essential. Listening carefully to the child's interests and sharing stories about their own lives in return, and then incorporating the child's interests into literacy activities during mentoring sessions are all important aspects of establishing mentor-child rapport (Ellis et al., 2001). Drawing on what seems to be a common interest and fascination with many children, having the dog to focus on during these early interactions may positively influence otherwise awkward moments common in new relationships. Sharing humorous stories about the dog, for example, talking about the child's own pet(s) or other animals in their lives, or reading a popular children's book featuring a dog may serve as a comfortable and meaningful starting place for the mentor and child to begin to get to know each other. Asking the child to bring an item that is important to him or her to the first session to share and talk about, with the mentor bringing the dog as his or her important gift to share may set the tone for a warm and positive atmosphere for learning.

One explanation for how an animal might influence early relationship dynamics between a child and a non-related adult comes from the early work of child psychologist Boris Levinson. In the late 1960's and 1970's, Levinson began to incorporate his dog into his therapy sessions. Levinson (1969) found that the dog acted as a 'social lubricant' between the therapist and child, which allowed for a more relaxed environment conducive to selfdisclosure on the part of the child. Because "the mentoring relationship is the tool for change in mentoring programs" (Rhodes, 2002) it is significant to consider that the inclusion of the dog as a 'social lubricant' may act as a catalyst for the relationship between the adult and child. Levinson (1987) suggests that the act of petting an animal serves two functions for the child: it draws attention away from him or herself and onto the dog, and allows the child to feel accepted and trusted by the dog who is allowing itself to be touched. Other researchers suggest that it may be the calming presence of the dog which causes a profound change in atmosphere, characterized by warmth and acceptance (Prothmann, Bienert, \& Ettrich, 2006) which in turn may encourage risk-taking, a necessary component of literacy learning for children (Cambourne, 1988).

\section{Continued Development of the Child-Mentor Relationship}

How a dog many influence relationship dynamics is not limited to the initial stages of the child-mentor relationship. Possibilities for how a dog might play an integral role in nurturing and deepening this unique adult-child relationship are illuminated when considered alongside Ellis, Small-McGinley, and De Fabrizio's (2001) four key aspects involved in the dynamics of mentorship relationships with children and nonrelated adults, adapted from Brendtro, Brokenleg, and Van Bockern's (1990) model, The Circle of Courage. 


\section{A relationship is not a feeling, but results from action, and the action or process entails}

some form of giving.

Ellis, Small-McGinley, and De Fabrizio (2001) emphasize that "it is through two lives coming together in this intentional and focused way that giving can occur spontaneously and even in spite of intentionality, and relationships and attachments can grow" (p. 177). These authors emphasize that beyond the varied reciprocal giving that can occur between mentors and children (i.e., small gifts, praise, and genuine care), it was "their very presence, their aliveness, and all of their nuanced responses to the child's aliveness" (p. 177) that supported the growth of these relationships. The nuanced interaction that Ellis and colleagues (2001) refer to here may be complimented by the profound attention, affection, and acceptance offered through a dog's range of subtle responses: the wag of a tail in greeting, a kiss on a small hand, or a dog's uncanny ability to notice subtle changes in mood, for example, which in turn may uniquely contribute to and/or reinforce attention and care between all participants.

\section{If helping adults are liked and admired by young people, the young people will be more} receptive to the adults' guidance, will seek their approval, and will be inclined to imitate their behaviours and attitudes.

Current research suggests that adults may seem more approachable and easier to talk to when they are accompanied by a dog. A recent study by Esteves and Stokes (2008) found that when school children were given opportunities to interact with a small dog as part of their daily lessons with their teacher, these interactions contributed to grade 2 students' positive communication with their teacher, both during these sessions and in the classroom following sessions with the dog. This study is significant because if a dog can positively influence a child's relationship with his or her teacher, then it is possible that a child's perception of and communication with his or her mentor may also be positively affected when the mentor is accompanied by a dog. Further, it is not difficult to envision how, as literacy mentors, our own close and loving relationship with our animals may serve as a positive model for the interaction possible between ourselves, the animal, and the child. As Fine and Eisen (2008) acknowledge, "my animals have taught me to be calm, gentle, and, ironically, more human with others" (p. 10). If a child's receptivity to guidance from a mentor stems from the establishment of a bond between the adult and child, then how might relationship and learning be shaped by the common bond the child and adult share with the animal, or by the unique bonds between group members (including the dog)?

\section{Helping adults must be able to bring warmth and stability to their attachments.}

Ellis, Small-McGinley, and De Fabrizio (2001) articulate that "much of the expression of warmth [in mentoring relationships] is nonverbal" (p. 180) and that "warmth itself may be a gift given, a way of interacting, or a state of being that resists definition" (p. 184). The nonverbal warmth Ellis and her colleagues refer to resonates with how children's interactions with dogs have been described in studies in therapeutic settings. Prothmann, Bienert, and Ettrich (2006) observe that dogs "seem to be able to be able to cause a profound change in the atmosphere...the children and adolescents may feel transported into an atmosphere that is characterized by warmth, acceptance, and empathy" (p. 275). In a recent study which took place in a classroom setting with students aged six to eleven years, one child described the dog as being "a better friend than humans, because [the dog] played with him more and accepted him no matter what. In particular, he noted that dogs 'forgave better' than humans" (Anderson 
and Olson, 2006, p. 45). Although further research is required, the non-verbal warmth that a dog can offer children within the mentor-child relationship may uniquely support children's literacy efforts.

\section{Common elements of positive relationships are caring, respect, responsibility and} knowledge (p. 193).

Finally, if "common elements of positive relationships are caring, respect, responsibility, and knowledge" (Ellis, Small-McGinley, \& De Fabrizio, 2001), then the reciprocal care and respect between child, dog, and mentor may uniquely support and nurture relationship development. How might feelings of responsibility, care for, and meaningful, purposeful knowledge about the dog influence relationship dynamics and learning? Anderson and Olson (2006) found that when children were provided with daily interaction with an adult and dog over the course of eight weeks, students' attitudes improved towards school and "facilitated students' learning lessons in responsibility, respect and empathy" (p. 35), lessons which generalized to their classroom relationships with peers.

Future research is required to explore how the inclusion of a dog in school-based literacy mentorship experiences might affect forms of gift giving within these relationships, how a dog might shift children's initial and long-term perceptions of their mentors, how warmth and stability are experienced within animal-assisted literacy mentoring sessions, and how care, respect, responsibility, and knowledge are demonstrated within these unique relationship dynamics.

\section{Goals and Best Practices of School-Based Mentorship Programs}

According to de Anda (2001), the purpose of the mentor-protégé relationship "is to provide a supportive adult role model who will encourage the youth's social and emotional development, help improve his/her academic and career motivation and achievement, expand the youth's life experiences, redirect youth from at-risk behaviors, and foster an improved self-esteem" (p. 98-99). With a clear emphasis on the development of a trusting and positive relationship, a mentor's role is to "help the student develop life skills; assist students in attaining additional resources; and help students in their ability to interact with others" (Dappen \& Isernhagen, 2006, p. 158). In this view of mentoring, it is expected that both a child's self-esteem and educational experience will be enhanced, with the mentor viewed as not only a tutor but as a trusted friend (Ellis, Small-McGinley, \& De Fabrizio, 2001). However, Randolph and Johnson (2008) warn that mentorship is most successful when 'best practice' is adhered to. As defined by Dappen and Isernhagen (2006):

...best practice is described as mentoring programs that include monitoring of program implementation, careful screening of mentors, matching mentors and [protégés] on at least one criteria, pre-match and ongoing training for mentors, program supervision, support for mentors, some structured activities, parent support and/or involvement, and expectations for frequency of contact and duration of the mentoring relationship (p. 152).

Emphasis on best practice in the design of mentoring programs is supported by a metaanalysis of 55 mentoring studies completed by Dubois, Holloway, Valentine and Cooper (2002). Dubois and colleagues (2002) clarify that best practices enable the development of a strong personal relationship between mentors and protégés which significantly enhances the effects of mentoring programs. Finally, it is essential to emphasize that although this discussion of 'best practices' offers generalized guidelines for school-based mentorship 
programs, what is defined as best practice can only be determined by thoughtful consideration of each individual school and community context.

\section{Goals and Best Practices of School-Based Animal-Assisted Literacy Programs}

Similar to school-based mentoring programs, the purpose of animal-assisted literacy mentoring programs is to support a child academically as well as enhance his or her selfesteem through a positive and supportive relationship with a gentle animal and a non-related adult. Orientation handbooks for animal-assisted literacy mentors urge volunteers to "provide an environment which makes reading a natural part of your pleasant social interaction," and advises that mentors do not "underestimate the power of [their] positive relationship to encourage and enhance [the] students' learning" (Pet Therapy Society of Northern Alberta: Paws for a Story, 2006, p. 15). Although existing animal-assisted school-based literacy programs offer a wealth of advice, tips, and strategies for the adult volunteer to assist them in supporting children's academic development and literacy skills in particular (see for example Reading Education Assistance Dogs: A Program of Intermountain Therapy Animals, 2007), careful attention needs to be paid to the necessary role of the adult as mentor, and the development of the mentor-protégé relationship specifically, when supporting a child during school-based animal-assisted literacy programs.

\section{Incorporating All Language Arts Strands}

Mentors involved in animal-assisted programs might consider possibilities for opening up the definition of literacy to include activities in addition to and outside of reading For example, animal-assisted literacy mentors might consider incorporating a wider range of activities into their sessions, and offer choices to the student with regard to the kinds of activities he or she is interested in participating in. Not only does incorporating a variety of literacy activities into mentoring activities more adequately encompass the Language and Literacy Researchers of Canada (2008) broad conception of literacy, but it may also contribute to relationship development between the literacy mentor, child, and dog because of the creativity, meaning, and sense of accomplishment often inspired while engaging in such activities. An overview of some suggested activities follows below in Figure 2, which can be adapted to suit individual children's interests and abilities.

Figure 2

\section{Incorporating the Six Language Arts into Animal-Assisted Literacy Sessions}

Reading

- Children and mentors can read a range of texts (fiction and non-fiction), including but not limited to crossword puzzles, cartoons, animal joke books, newspaper articles, and children's magazines.

- Children can practice reading a developing piece of original writing to the dog as a 'non-judgemental' audience

- Children can be encouraged to read a recipe and follow the instructions to bake home-made dog treats 5 .

- Students can include the dog in story writing. For example, the child may

Writing imagine the dog in different settings and write about what he/she might do.

\footnotetext{
${ }^{5}$ Volunteers should ensure that the liability insurance that their particular animal-assisted literacy program has allows for the animal handler to provide treats to the dogs during their sessions before engaging in this activity.
} 


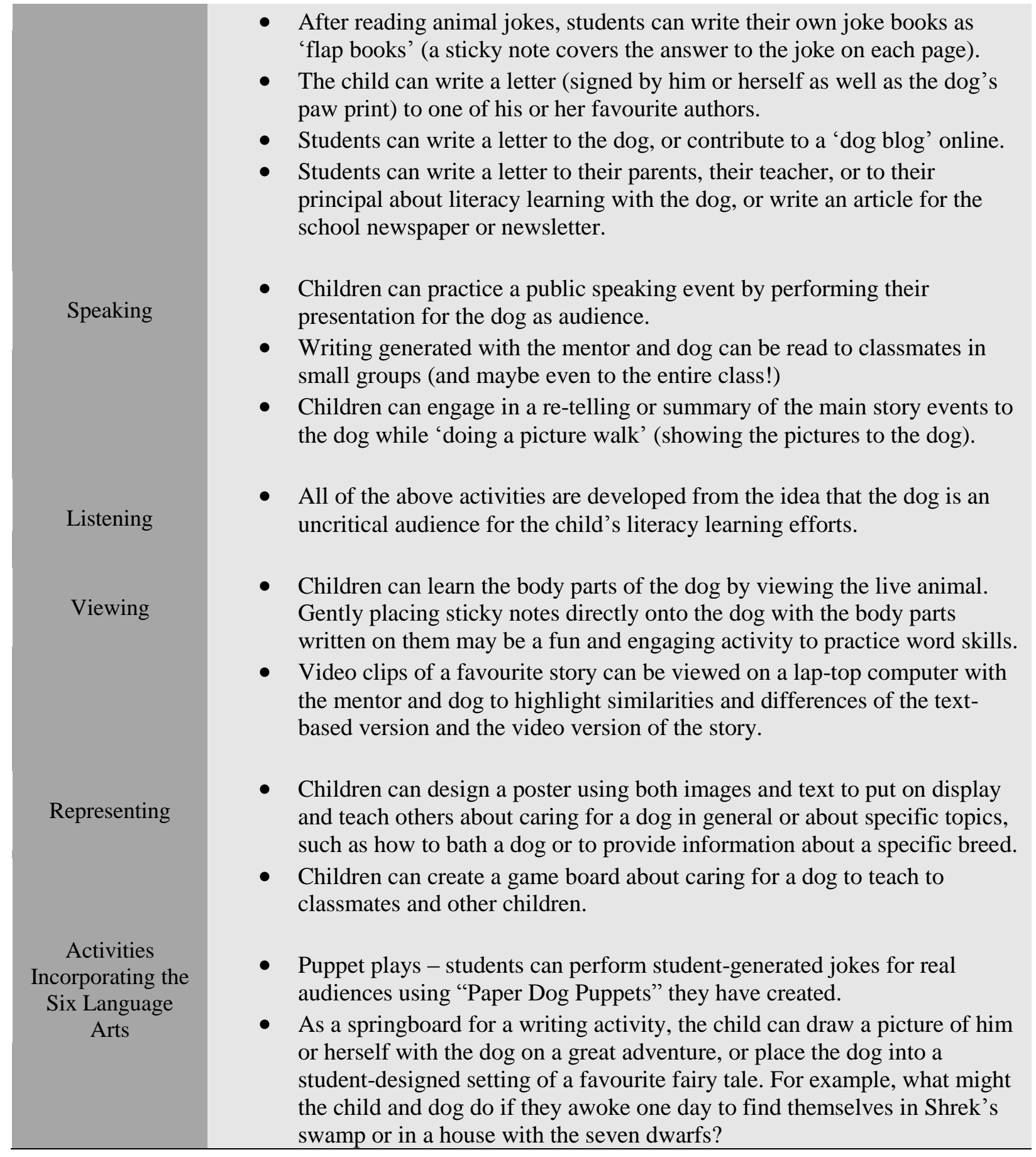

Particularly because best practices enable the development of a strong personal relationship between mentors and protégés which significantly enhances the effects of mentoring programs (Dubois, Holloway, Valentine, \& Cooper, 2002), further research is required to establish whether or not an emphasis on best practices is consistently maintained in animal-assisted literacy mentoring programs. As defined by the R.E.A.D. program (2007), animal-assisted literacy mentors should display an enjoyment of children and a love of reading, demonstrate compassion, sensitivity, flexibility and patience, and must commit to weekly mentoring sessions as a role model and to regular grooming of their animal. 
Participating mentors and their dogs must be trained to be "registered therapy teams screened, tested, and qualified in temperament and skills" (R.E.A.D., 2007, p. 37). However, similar to traditional mentoring programs, the process for matching of mentors and protégés is largely dependent on the volunteers available for participation in the programs. Animalassisted mentors have basic animal-assisted therapy training, three hours of R.E.A.D. training, and ongoing mentoring training as they become familiar with the program. Finally, parental support is necessary for animal-assisted literacy mentor programs to take place, particularly because children may have allergies to animals, may be fearful of animals, or may not be allowed to touch animals due to cultural or religious reasons (Friesen, 2009; Jalongo, 2005; R.E.A.D., 2007).

\section{How Animal-Assisted Mentoring may Provide Valuable Educational, Emotional, and Social Support for Children}

\section{A Spirit of Prevention, Not Remediation}

With an overall focus on a child's well-being, school-based mentoring programs open to all children emphasize prevention of academic and social/emotional difficulties rather than remediation (Dubois, Holloway, Valentine, \& Cooper, 2002; Ellis, Small-McGinley, \& De Fabrizio, 2001; Randolph \& Johnson, 2008; Small-McGinley, 2000). This focus on prevention is significant for children's literacy because historically, "educators have generally waited for some children to fail at school and then offered remediation" (Ellis, Small-McGinley, \& De Fabrizio, 2001, p. 43). Learning with a mentor while accompanied by a therapy dog may uniquely place the child in a position of power with an emphasis on the positive, or on possibilities, rather than a focus on deficits. In encouraging the child to get to know and read to the dog, the focus is taken off the child's skill deficit and re-directed towards showing the dog what he/she knows. For example, many animal-assisted literacy mentors suggest that when a child struggles with a word that they try to teach the dog the word together because the dog doesn't know that word either (Jalongo, 2005). Although both the child and the adult likely know that it is not probable that the dog will actually learn the word, it is the redirection of focus off of the child's own difficulties and the humour and fun of trying to teach a cuddly friend which adds an element of light-heartedness to the atmosphere. In reading to and empowering the child as teacher to an uncritical audience, but with the available support of the adult mentor if requested, the child can be nested in a supportive and enjoyable atmosphere for learning.

\section{Additional Literacy Support for Children}

Particularly in an economic climate of crisis, many North American families are struggling not only with financial restraints but with a lack of the stability and peace of mind that accompanies the loss of economic security. Further, Rhodes, Reddy, Roffman, and Grossman (2005) argue that changing family patterns, large class sizes, and more disparate communities have negatively affected the number of caring adults in children's lives, particularly in urban environments. As Pressley (2001) acknowledges, "if a child's world is...filled with people who will work with her or him (i.e., tutor the child), early literacy development is also more certain" (p. 28). Finally, although teachers ask parents to read with their children at home each night, some parents simply do not have the time or the inclination to do so (Pressley, 2001). It also may be that parents are not always the best teachers for their children. Despite parents' best intentions, children may be reluctant to read with their parents 
because many children are able to detect even the slightest hint of their parents' disapproval.

\section{Individualized Student Support}

Randolph and Johnson (2008) acknowledge that schools are experiencing increased pressures to be accountable for student learning, yet "they have also experienced a substantial reduction in school resources for non-academic programs. Volunteer mentors can provide much additional support to help alleviate these dilemmas" (p. 177). Ellis, Hart, and SmallMcGinley (1998) suggest that having an extra person around for a student to talk to "brings great relief and comfort and frees the student to get on with his or her day and become available for constructivity" and is a prerequisite for students to make the most of their educational experience (p. 229). Similarly, opportunities to 'talk to' an animal in the school setting may provide children with a unique form of comfort and support. As Melson (2001) acknowledges, "dialogue with [animals] offers a time-out from the anxieties of human exchange... despite most children's acknowledgement that pets cannot literally comprehend what they are saying, children have the feeling of being heard and being understood" (p. 51).

\section{Multi-Sensory Learning Experiences}

Particularly at a time when teachers (and especially male teachers) have been warned against physical touch with their students (Frank, 2001), the multi-sensory experience offered to a child when provided supervised opportunities to hug and touch a soft, furry animal may offer untold benefits in the school setting. Although further research is required, one study indicates that conversation with children while interacting with a small animal seems to invite questioning, personal stories, and naturally occurring 'teachable moments' (Hunt \& Hart, 2001). This research seems to suggest that when children are provided opportunities for multisensory interaction with animals, including touch, they may be more likely to engage in cognitive thinking processes such as questioning, and may be more likely to relate the encounter to their own experiences.

\section{Nurturing Children's Imaginations}

Spencer (2003) proposes that imagination "is not something separate or extra that their teachers add to [children's] learning" (p. 107). Rather, imagination is at the heart of children's meaning-making when they work with text, particularly as they engage with imaginative children's literature. Spencer emphasizes that children's authors create "worlds of possibilities" for children's imaginations, and, as explained by Vygotsky (1978), "use imaginative language as they make worlds of play and stories" (p. 110). The popularity of children's books featuring personified animals, Disney movies with animal stars such as Mickey Mouse and Bambi, and the popularity of stuffed animals provide several examples of children's common fascination with animals (Friesen, 2010; Melson, 2001). If so many children willingly enter into the imaginary worlds of Disney-animated animal characters, it may not be difficult to envision the playful possibilities for children when they are invited to read to a responsive yet unconditional audience such as a dog.

Further, Church (2006) notes that many young children keep one foot planted both inside and outside of reality, as is illustrated by their wavering belief in Santa Claus. Rosoff (2007) defines play as "stepping out of the confines of reality to imagine new identities and scenarios" (p. 59), and points out that play offers a safe method of practicing necessary skills for later use. As illustrated by the examples offered in Figure 1, because play offers both an escape from and a preparation for reality (Ackerman, 1999; Rosoff, 2007), children may 
experience an unconventional freedom during animal-assisted literacy learning sessions to practice and internalize important literacy skills.

\section{The Ripple Effect: Benefits Beyond the Child}

It should also be noted that the benefits of mentorship may not only be enjoyed by the child, but may positively extend into the community through a mutually satisfying experience for the mentor and for the participating animal. In addition to the obvious enjoyment a mentor may experience through developing a meaningful relationship with a non-related child, Jackson (2002) acknowledges that mentoring programs can assist adults in learning to more carefully listen to children, how to effectively coach and give feedback to children, and how to act as role models for successful problem-solving and appropriate behaviour. For the animals themselves, benefits can be derived from the increased socialization from being around children on a regular basis, and from more empathetic treatment by children as a result of naturally occurring teachable moments about the unique needs of animals which often arise through supervised interaction with an animal. As Jalongo (2008) acknowledges, although dog bites are common among children they can be prevented through age-appropriate modeling of empathetic and appropriate behaviour by a responsible adult.

In addition, the knowledge children glean from these positive experiences with animals at school may have direct implications for their home lives. Along with the literacy learning experienced during such sessions, increased possibilities for spontaneously generated lessons in ecology and empathy for other living things, and potential for transference of knowledge for how to care for and interact with an animal such as a dog are likely to be shared at home with siblings and parents. Given that over $50 \%$ of Canadian families own pets (Ontario Veterinary Medical Association, 2007) with dogs and cats being most common in homes with children (Melson, 2001), it is significant that the positive tacit learning children pick up from animalassisted literacy learning sessions may carry over into their experiences with animals outside of the school context.

\section{Closing Remarks}

Ultimately, the success lies in the magic that can unfold between mentor and child"

(Ellis, Small-McGinley, \& De Fabrizio, 2001, p. 113).

Literacy research indicates that when a child is afraid to take risks, it is very difficult for literacy learning to occur (Cambourne, 1988). Animal-assisted literacy mentorship opportunities may be particularly valuable for the child who needs gentle and focused attention not otherwise possible in a busy classroom. Some children are painfully shy, while still others have likely not been inspired or given enough one-on-one adult support to engage and succeed in literacy. In short, many children would likely smile at an opportunity to learn with a mentor and therapy dog, relationships that children may view as being outside of the usual and complex expectations of school and family life. Further research is required to achieve a deeper understanding of the dynamics undergirding animal-assisted literacy learning and to explore the significance of animal-assisted learning experiences for children and mentors. However, the global popularity of animal-assisted literacy programs uncovers a tension between the literacy support that children are currently receiving in classrooms and the kinds of assistance they might need or want. A closer examination of the roles of the adult, the child, and the dog in animal-assisted literacy programs may assist literacy educators in gaining a more comprehensive understanding of possibilities for this pedagogical innovation. 


\section{References}

Ackerman, D. (1999). Deep play. New York, NY: Random.

Anderson, K. L., \& Olson, M. R. (2006). The value of a dog in a classroom of children with severe emotional disorders. Anthrozoos, 19(1), 35-49.

Animal Angels (2010). Retrieved on September 1, 2010 from http://www.animalangels.org.in/aa/Times-NIE.htm

Animals Asia Foundation (2010). Retrieved on September 1, 2010 from http://www.animalsasia.org/index.php?UID=MTOQ9HRELNU

Biancarosa, C., \& Snow, C. E. (2006). Reading next - A vision for action and research in middle and high school literacy: A report to Carnegie Corporation of New York $\left(2^{\text {nd }}\right.$ ed.). Washington, DC: Alliance for Excellent Education.

Brendtro, L., Brokenleg, M., \& Van Bockern, S. (1990). Reclaiming youth at risk: Our hope for the future. Bloomington, IN: National Education Service.

Brodkin, A. M., \& Coleman, M. (1996). He's trouble with a capital T. Instructor, 105(7); 1821.

Cambourne, B. (1988). The whole story: Natural learning and the acquisition of literacy in the classroom. Auckland, NZ: Ashton Scholastic.

Church, E. B. (2006). Fairy tales and dragons. Scholastic Parent \& Child, 13(5), 62.

Dappen, L. \& Isernhagen, J. (2006). Urban and nonurban schools: Examination of a statewide student mentoring program. Urban Education, 41(2), 151-168.

de Anda, D. (2001). A qualitative evaluation of a mentor program for at-risk youth: The participants' perspective. Child and Adolescent Social Work Journal, 18(2), 97-117.

DuBois, D., Holloway, B., Valentine, J., \& Cooper, H. (2002). Effectiveness of mentoring programs for youth: A meta-analytic review. American Journal of Community Psychology, 30(2), 157-197.

Ellis, J., Hart, S., \& Small-McGinley, J. (1998). The perspectives of "difficult "students on belonging and inclusion in the classroom. Reclaiming Children and Youth, 7(3), 14246).

Ellis, J., Small-McGinley, J., \& De Fabrizio, L. (2001). Caring for kids in communities: Using mentorship, peer support, \& student leadership programs in schools. New York, NY: Counterpoints.

Esteves, S. \& Stokes, T. (2008). Social effects of a dog's presence on children with disabilities. Anthrozoos, 21(1), 5 - 15.

Fine, A. H. \& Eisen, C. J. (2008). Afternoons with Puppy: Inspirations from a therapist and his animals. West Lafayette, IN: Purdue University Press.

Frank, B. (2001). Real men or real teachers: Contradictions in the lives of men elementary school teachers. McGill Journal of Education, 36(2), 173-175.

Friesen, L. (2010). Animals in children's literature: A powerful motivator for literacy learning. Focus on Elementary: Association for Childhood Education International, 22(2), 1-7.

Friesen, L. (2009). Exploring animal-assisted programs with children in school and therapeutic contexts. Early Childhood Education Journal, 37(4), 261-267.

Hines, L. (2003). Historical perspectives on the human-animal bond. American Behavioral Scientist, 47(1), 7-15.

Hunt, S., \& Hart, L. (2001). Role of small animals in social interactions between strangers. The Journal of Social Psychology, 132(2), 245-256.

Intermountain Therapy Animals (2010). R.E.A.D. Retrieved on August 25, 2010 from http://www.therapyanimals.org/R.E.A.D.html 
Jackson, Y. (2002). Mentoring for delinquent children: An outcome study with young adolescent children. Journal of Youth and Adolescence, 31(2), 115-122.

Jalongo, M. (2008). Beyond a pets theme: Teaching young children to interact safely with dogs. Early Childhood Education Journal, 36(1), 39-45.

Jalongo, M. (2005). What are all these dogs doing at school? Using therapy dogs to promote children's reading practice. Childhood Education, 81(3), 152-158.

Jalongo, M., Astorino, T., \& Bomboy, N. (2004). Canine visitors: The influence of therapy dogs on young children's learning and well-being in classrooms and hospitals. Early Childhood Education Journal, 32(1), 9-16.

Kellert, S. \& Wilson, E. (1993). The biophilia hypothesis. Washington, DC: Island Press. Language and Literacy Researchers of Canada (2008). Position statement. Retrieved from http://www.csse.ca/CACS/LLRC/docs/LLRCPositionStatement.pdf, May, 2008.

Levinson, B. (1969). Pet-oriented child psychotherapy. Springfield, Illinois: Charles C. Thomas, Bannerstone House.

Levinson, B. (1987). Foreword. In P. Arkow (Eds.) The loving bond: Companion animals in the helping professions (pp. 1-20). Saratoga, CA: R \& E Publishers.

Limond, J., Bradshaw, J., \& Cormack, K.F. (1997). Behavior of children with learning disabilities interacting with a therapy dog. Anthrozoos, 10(2/3), 84-89.

McGeorge, C. W. \& Whyte, M. (1996). Boomer goes to school. San Francisco, CA: Chronicle Books.

McKinnon, J. (2009). The reading lab. Retrieved August 4, 2009 from Australia Today. http://www.australiatodaymag.com.au/articles/the_reading_lab/

Melson, G. F. (2001). Why the wild things are. Cambridge, MA: Harvard University Press.

Nimer, J., \& Lundahl, B. (2007). Animal-assisted therapy: A meta-analysis. Anthrozoos, 20(3), 225-238.

Ontario Veterinary Medical Association (2007). Pets: An integral part of the family. Retrieved February 6, 2009, from www.ovma.org/pet_owners/ownership_benefits/part_of_family.html

Pet Therapy Society of Northern Alberta (2006). Paws for a story: Volunteer orientation. document, July, 2006.

Pressley, M. (2001). Effective beginning reading instruction. Executive Summary and Paper Commissioned by the National Reading Conference. Chicago, IL: National Reading Conference.

Prothmann, A., Bienert, M., \& Ettrich, C. (2006). Dogs in child psychotherapy: Effects on state of mind. Anthrozoos, 19(3), 265-277.

Randolph, K. \& Johnson, J. (2008). School-based mentoring programs: A review of the research. Children \& Schools, 30(3), 177-185.

Reading Education Assistance Dogs (2007). A program of Intermountain Therapy Animals. Salt Lake City, UT: Intermountain Therapy Animals.

Rosoff, A. (2007). The reality of unreality: Using imagination as a teaching tool. English Journal, 96(3), 58-62.

Rhodes, J. (2002). Stand by me: The risks and rewards of mentoring today's youth. Cambridge, MA: Harvard University Press.

Rhodes, J., Reddy, R., Roffman, J., \& Grossman, J. (2005). Promoting successful youth mentoring relationships: A preliminary screening questionnaire. The Journal of Primary Prevention, 26(2), 147-167. 
Small-McGinley, J. (2000). A case study of mentoring relationships between children and non-related adults in a school-based mentorship program. (Doctoral dissertation). Retrieved from http://proquest.umi.com.login.ezproxy.library.ualberta.ca

Spencer, M. M. (2003). What more needs saying about imagination? Journal of Adolescent \& Adult Literacy, 47(1), 106-112.

Vygotsky, L. S. (1978). Mind and society. Cambridge, MA: Harvard University Press.

Wilson, E. O. (1984). Biophilia: The human bond with other species. Harvard University Press, Cambridge, England.

Acknowledgements:

This work was supported by the Social Sciences and Humanities Research Council of Canada; and the Killam Trust.

\section{AUTHOR BIOGRAPHY}

Lori Friesen is a PhD candidate in Elementary Education at the University of Alberta. She earned her MEd at the University of Lethbridge and wrote The Beginning Teacher's Handbook for Elementary School as the final project for her degree. Lori has ten years' teaching experience, including one year teaching for the Faculty of Education at the University of Lethbridge. 